\title{
Discourses on menopause - Part I: Menopause described in texts addressed to Danish women 1996-2004
} Vol 12(2): 157-175

\author{
Lotte Hvas and Dorte Effersøe Gannik \\ University of Copenhagen, Denmark
}

\begin{abstract}
A BSTRACT To understand Danish women's very different ways of interpreting menopausal experiences and the way they construct meaning relating to menopause, it is necessary to include the context in which meaning is constructed as well as the background of cultural attitudes to menopause existing in the Danish society. Using documentary material, the aim of this article was to describe different discourses on menopause in Denmark that present themselves to menopausal women, and to discuss how these discourses may affect women's identity and constitute their scope of action. One hundred and thirty-two pieces of text under the heading or subject of 'menopause' or 'becoming a middle-aged woman', published from 1996 to 2004, were included. All material was addressed to Danish women, and consisted of booklets and informational material, articles from newspapers and magazines and popular science books. Seven different discourses on menopause were identified: the biomedical discourse; the 'eternal youth' discourse; the health-promotion discourse; the consumer discourse; the alternative discourse; the feminist/ critical discourse; and the existential discourse. The biomedical discourse on menopause was found to be dominant, but was expanded or challenged by other discourses by offering different scopes of action and/or resting on different fundamental values. The discourses constructed and positioned individual women differently; thus, the women's position varied noticeably from one discourse to another. Depending on the discourse drawn upon, the woman's position could be that of a passive patient or that of an empowered woman, capable of making her own choices in relation to her health.
\end{abstract}

KEYWORDS discourse analysis; menopause; midlife; social construction; women

A D D R E S S Lotte Hvas, Department of General Practice, Centre of Health and Society, University of Copenhagen, Øster Farimagsgade 5, PO 2099, DK 1014 Copenhagen K, Denmark. [Tel: +45 55991959; fax: +45 55991992; e-mail: lotte.hvas@dadlnet.dk] 


\section{Introduction}

How do women experience menopause, and what are their wishes and experiences in relation to the health care system? In order to answer these questions a study combining quantitative and qualitative data has been conducted in Denmark from 1996-2004 (Hvas, 2006; Hvas et al., 2003, 2005). To understand Danish women's very different ways of interpreting menopausal experiences and the way they construct meaning relating to menopause, it is necessary to include the context in which meaning is constructed as well as the background of cultural attitudes to menopause existing in the Danish society. This cultural understanding is reflected in the way lay people, friends, family, colleagues, but also doctors, health practitioners and media people speak about menopause, and it can be captured by means of a discourse analytic approach.

Discourse literally means 'conversation' and refers to the view that things acquire meaning according to how we talk about them (Phillips and Jorgensen, 2002). The words we choose are important, because they reflect values that colour and constitute what we are talking about. Different ways of talking and writing about menopause thus shape different images of menopausal women, and different discourses facilitate and limit, enable and constrain what can be said, by whom, where and when (Willig, 2003).

Drawing on documentary material, the aim of this article is to describe different discourses on menopause in Denmark as they present themselves to menopausal women. We subsequently discuss how different discourses may affect women's identity and constitute their scope of action.

In a subsequent article entitled 'Discourses on menopause - Part II: How do women talk about menopause?' (Hvas and Gannik, 2008) we present the results from in-depth interviews with 24 women.

\section{Menopausal discourses described in earlier studies}

Though every woman will experience menopause if she lives long enough, the cessation of menstruation has been conceptualized differently over time and across cultures, and different meanings have been ascribed to this phase. Many, primarily sociological, anthropological and feminist researchers have shown that menopause has become increasingly medicalized in the western world since the discovery of sex hormones in the late 1930s (Bell, 1987; Ferguson and Parry, 1998; Greer, 1991; Kaufert and Lock, 1997; Lock, 1993; Lupton, 1996; Stephens et al., 2004). In the prevailing, predominantly biomedical discourse, menopause is most often couched in negative terms focusing on hormone deficiency, symptoms, risk factors, treatment, disease and decay. But the medical approach is paralleled by other discourses. For example, several researchers show that the negative images are contradicted by women's own experience which stresses the positive aspects of menopause 
(Bertero, 2003; Daly, 2001; Dennerstein et al., 1994; Hvas, 2001; Utian and Boggs, 1999).

In an essay from 1996, Lupton described how different discourses addressing hormone treatment played a role in the construction of the menopausal body (Lupton, 1996). Hormones could be seen as 'an ageretarding commodity' like expensive moisturizers or cosmetic surgery, as well as a 'health-protective strategy'. Hormones could also be seen as unnatural substances to be avoided or, on the contrary, as an opportunity to control 'ill-health and death'. The image of the menopausal woman differed accordingly.

Shoebridge and Steed analysed two daily newspapers and four women's magazines in Australia during a 10-year period to identify dominant discourse about menopause. They found that: 'with few exceptions, discourse drew on and reinforced schemata of ill-health, psychological disturbance, vulnerability, decrepitude, biological determinism and illness management' (Shoebridge and Steed, 1999).

Similarly, Gannon and Stevens examined menopause in American popular print media during 1981-94 by locating all articles indexed under 'menopause'. They found that 'almost all articles were focused on menopause as a negative experience or illness and in need of medical treatment' (1998).

Lyons and Griffin (2003) examined four British self-help books on menopause in a constructionist analysis on how menopause and women's bodies were represented. Menopause was constructed as a deficiency illness in all four texts, but the 'illness' discourse was challenged by a 'natural' discourse in three of the books. They also found that the medical profession was constructed as the primary source of expertise on menopause and women's bodies, but responsibility for its 'management' as a chronic condition lay solely with the individual women. Stephens et al. (2004) conducted a discourse analysis to explain variation in the use of hormones among women in New Zealand. They analysed qualitative data from seven focus group discussions about hormone replacement therapy (HRT) and described socially available 'interpretive repertoires', that is, different possible ways of interpreting a phenomenon, and found that 'different repertoires provide different subject positions for speakers', for example 'a potential victim, a patient, or a woman in control' (Stephens et al., 2004).

\section{Discourse analysis as a theoretical approach}

'Discourse analysis' is rooted in multiple disciplines like philosophy, sociology and linguistics. It owes part of its popularity to the pioneering work of the philosopher Michel Foucault but has been developed further by his followers (e.g. Fairclough, 1992; Laclau and Mouffe, 1985; Potter and Wetherell, 1987). 
Discourse analysis structures areas of knowledge and social practice (Fairclough, 1992) by offering a special way of observing the world and of addressing questions to the material analysed (Nexø and Koch, 2003). Discourse manifests itself in all symbolic forms of language and everything spoken, sung, written, visualized and so on can be analysed (Fairclough, 1992; Phillips and Jorgensen, 2002). The key question asked is: Which reality is constructed by talking about a subject in a specific way and by using certain concepts instead of others (Nexø and Koch, 2003)?

Discourse analysts adhere to the basic social constructionist premise that knowledge is not a mere reflection of reality. It is a discoursive construction, and different knowledge regimes (or epistemes) determine what should be accepted as truth or rejected as false. Different discourses establish different positions among which some hold the authority to speak decisively about what is true or false. By way of their right to define truth, some persons are ascribed more power than others, and power is thus a central concept in discourse analysis. In medical discourse, a professor with a PhD has a position from which (s)he can speak about what is 'true' with great authority, while others (e.g. alternative therapists) are excluded from that discussion. Other discourses may breed from, and in turn create, different and even contradictory positions where, for example, the alternative therapist enjoys great authority.

The concept of power used in discourse analysis has a different meaning from that used in classical sociological theory. It is not defined by exclusion and oppression, but becomes productive when, through attained positions of power, something is achieved. In this way the discourse 'works' or as expressed by Foucault himself:

What makes power hold good, what makes it accepted, is simply the fact that it doesn't only weigh on us as a force that says no, but traverses and produces things, induces pleasure, forms knowledge, produces discourse. It needs to be considered as a productive network which runs through the whole social body, much more than a negative instance whose function is repression. (1972: 119)

In critical discourse analysis (Fairclough, 1992), the main issue is how language users actively create and change discourses and thereby promote social and cultural change. When a discourse has become dominant, certain beliefs, ideas and actions are taken for granted. Fairclough points out that the potential for change is reduced when the self-evident goes unquestioned. However, through discoursive struggle, disclosing other discourses, social change can occur with the associated changes in patterns of power.

Examination of texts on menopause allows recognition of discoursive changes and examination of how other values, meanings and actions gradually force changes upon the strictly biomedical approach. In the interplay between discourses, social consequences become visible: when two or more discourses, each interpreting reality differently, contend in the same field, it becomes possible to inquire into the consequences of accepting one or the other (Phillips and Jorgensen, 2002). 


\section{Methodology}

\section{Description of the included texts}

Printed texts about menopause available to Danish women were collected, namely, texts originating from newspapers, magazines or books or distributed to menopausal women by doctors or pharmacies, including booklets, informational material and advertisements.

All relevant documentary material was included during an eight-year period (1996-2004) by the principal author (LH). The criteria were: written texts or illustrations/pictures under the heading or subject of 'menopause' or 'becoming a middle-aged woman'. Material should be addressed to Danish women; thus, all texts are in Danish. No texts encountered were excluded, except copies.

The collection consists of 132 different pieces of text and pictures. The material consists of (numbers in brackets):

- Booklets or informational material to women on menopause (11), hormone therapy (16) or alternative treatment (6).

- Articles from daily newspapers (49) and magazines (33).

- Books on menopause and ageing (17), mainly popular science books, debate books or more 'alternative' self-development books.

Intended audience The booklets and information material as well as the books on menopause all have menopausal or premenopausal women as their primary focus. Some of the articles from daily newspapers and magazines also address menopausal women, but only as a part of a broader audience.

Authors Many booklets are produced or sponsored by the pharmaceutical companies, and supposed to be handed out by physicians or at the pharmacy in connection with counselling on menopause and hormone therapy. These texts are often written by gynaecologists on behalf of pharmaceutical companies, but the author is often anonymous. There were no direct advertisements for hormone therapy as advertisements for prescription drugs is prohibited in Denmark. Other information material and booklets take the form of public health information and are produced by the health authorities. Booklets or advertisements on alternative therapy are mostly produced by companies selling herbal medicine. The newspapers and the magazine articles are mostly written by journalists, but they often refer to medical experts on the subject. Debate articles are also found in the newspaper and magazine articles, and they are mainly written by citizens and 'opinion makers' who take part in the debate through letters to the editor. The books on menopause were written by different 'experts': doctors, psychologists, alternative therapists as well as feminists and other 'opinion makers'. 
health: 12(2)

Contents Most of the material addresses menopausal symptoms and treatment. Description of hormone therapy or herbal medicine, as well as the arguments for and against hormone therapy, take up considerable space in books, booklets and information material.

Most of the booklets on hormones were issued before the publishing of the results from the Women's Health Initiative (WHI, 2002), which exposed the question of hormone therapy side-effects and subsequently changed the recommendations concerning use of hormones. After 2002, material from the pharmaceutical industry has been sparse, whereas texts presenting results from the WHI and the debate they raised dominated in newspaper articles.

\section{Analysis of the texts}

Discourse analysis is not a method of data analysis in any simple sense. Rather, it offers a way of thinking about the role of discourse in the construction of social and psychological realities and this, in turn, can help us approach research questions in new and productive ways (Willig, 2003).

Few discourse analysts provide any concrete statement on method. However, Willig (2003) provides us with a manageable stepwise guide to what she calls a Foucauldian discourse analysis. By reading and structuring the material through the lens of discourse analysis, and by modifying Willig's method, we structured our analysis as follows:

- Identification of different ways in which discoursive objects were constructed in the texts, i.e. menopause, menopausal women, hormone therapy, supplementary medicine, doctors and so on. Hormone therapy was for instance constructed as a 'health-protective remedy', 'unhealthy toxin', 'rejuvenation treatment'.

- Identification of different values and goals inherent in the discoursive construction: What is gained from constructing the object in this particular way? For example, health, avoidance of fractures, autonomy, harmony.

- Identification of subject positions offered by the various constructions of the discoursive objects within the text. Each subject position has its own rights and duties. For example, a passive patient or an empowered woman.

- What can be said and done within the specific discourse? What opportunities for action does it provide to the women (and the doctors)? For example, a woman may passively listen to a doctor's advice, or she can be the active part in seeking alternative information.

\section{Seven different discourses on menopause were identified}

Seven different discourses on menopause could be identified and delimited, each having its own fundamental values, options for action and way of positioning the women: the biomedical discourse; the 'eternal youth' discourse; the health discourse; the consumer discourse; the alternative discourse; the feminist/critical discourse; and the existential discourse. A more detailed 
analysis follows. Each description is preceded by a text sample, translated into English. Examples were chosen to show the discourse in question in its 'purest' possible form, even if no text exclusively drew upon a single discourse.

\section{Biomedical discourse}

In connection with menopause the ovaries stop producing oestrogen - one of the female sex hormones. This has different effects on the tissues and functions of the body. Many menopausal women (but not all) experience different symptoms ... Symptoms can be divided into two different groups: those which are due to oestrogen deficiency for sure and those that are not, but which appear in the same period anyhow.

Symptoms that are due to oestrogen deficiency include: hot flushes, excessive sweating, night sweats, insomnia, palpitations, bleeding irregularities, vaginal dryness, pain during sexual intercourse, incontinence, urinary tract infections, osteoporosis, fractures, cardiovascular diseases.

Symptoms that are not for sure due to oestrogen deficiency include: irritability, depression, lack of concentration, tiredness, headache, decreased libido, low back pain.

If you chose hormonal treatment, you must consult a physician regularly, the first time after three months, subsequently once a year. If you follow the recommended controls, tumours - benign as well as malignant - will be detected early. (Gynaecologists in a health magazine, Felding and Christoffersen, 2004: 18)

According to the biomedical discourse, the aim is to strive to avoid disease and premature death, which can be achieved by treatment or prevention. This discourse is based upon the positivist assumptions of natural science, according to which any disease has a cause, and if that cause is known, one can search for a method of curing or preventing the disease or condition. Menopause is seen as a deficiency syndrome caused by a decline in hormones: menstruation stops, various symptoms occur and the risk of future diseases (especially osteoporosis) rises. Conditions experienced by women even in advanced age are directly linked to hormonal changes due to menopause, as when fractures are called 'post-menopausal osteoporosis'.

Ageing is spoken about in terms of a weakening, with a focus on biological decay and an increased morbidity, the suffering of osteoporosis and cardiovascular diseases. In the medical database Medline, 'ageing' is defined as 'The gradual irreversible changes in structure and function of an organism that occur as a result of the passage of time'. By linking the increased weakness of the aged body to the cessation of menstruation, menopause acquires a negative meaning no matter what women actually experience.

Symptoms and diseases are described in the biomedical discourse in terms of 'technical failure', that is, something happening within the body and its organs independently of the person's thoughts or feelings: the oestrogen level drops, the vaginal mucosa gets thinner and the bones become 
more brittle. The woman's role is passive. Her body is subjected to the fact that her ovaries are not producing any oestrogen and she becomes the victim of inevitable decay. She is also passive in relation to the doctors whose role it is to care for her and to control her body. She is awarded the role of a patient, and the medical expert enjoys the ability to prescribe the best treatment and examination, using statements that appear to be indisputable facts such as, 'If the recommended procedures are followed, tumours will be discovered early.'

The texts appear to be value-neutral. They use rational arguments that are often reinforced by anatomical sketches of the woman's pelvis or microscope pictures of the vaginal mucosa, osteoporotic bones or other diseased organs. Women as persons are excluded from the picture: decay occurs within the body independently of the individual woman. Some illustrations show women suffering from hot flushes or excessive sweating, or women suffering from future illnesses, for example, a hunchbacked crone, a woman in a hospital bed with her leg in a cast. Finally, healthy women are shown seemingly conveying a message of evident health owing to the treatment received.

The biomedical discourse affects just about every text on the subject of menopause. It is found in its 'purest' form in texts written by doctors, particularly those written by gynaecologists, in booklets or informational material on the subject of hormonal treatment. However, newspaper and magazine articles also relate to the biomedical discourse by referring to the ovaries' declining production of oestrogen, and the option of hormonal treatment. Pharmaceutical companies are often active proponents of the biomedical discourse, by way of publishing booklets stressing the possibility of hormonal treatment. However, the companies do not enjoy a position that allows them to state what 'true' knowledge is. They overcome this difficulty by utilizing medical experts to convey the text or by referring to scientific medical studies.

\section{Eternal youth discourse}

Some radiate lust, others accept the inner nun. It is a question of hormones.

Some women resign and feel that holding on to sex is an embarrassment. They stop caring and let 'the inner nun' accept the situation. This obviously creates problems in their sexual relationships. Some also have trouble accepting that with the help of new drugs they can function well for a long time yet. They have to learn to view hormone replacement as a natural thing; they get what the postmenopausal body no longer produces. (Magazine interview, with an executive in a pharmaceutical company, Skodsborg, 2001: 13)

Central to late modern western society is the ideal of staying youthful. Youth and youthfulness are admired and longevity promoted, while ageing and old people are belittled and made invisible (Blaakilde, 2001). In this discourse menopause is a negative symbol of age, and the last menstruation 
is considered a threat, a milestone in an unwanted ageing process. This threat can be counteracted by cosmetic surgery, moisturizers, hair colouring remedies and hormones, which become age-retarding commodities, or 'life elixirs' that can preserve vitality, agility and elasticity of the skin. The trend of trying to buy 'eternal youth' is strong in the USA, and plays an ever more important role in western European culture, as seen for instance in the increased demand for injections of Botox to remove eye wrinkles (Tsao, 2003). This discourse borders on the biomedical discourse where ageing is also seen as a sign of bodily decay, but the objective in the 'eternal youth' discourse is not just avoidance of weakening and diseases, but conservation of sexuality and physical attractiveness.

This discourse is primarily represented in advertising and informational material on hormones and in magazine articles. The illustrations for instance show old women with canes or the microscope pictures mentioned above used as signs of decay. Advertising drawing on this discourse uses positive imagery of youthful women or symbolic representations, for example a freshly flowering rose.

\section{Health-promoting discourse}

Exercise strengthens. Keeping in physical shape and exercising the whole body increases the chances of avoiding osteoporosis.

It is important to remember that the whole body needs to be exercised. The form of exercise is of less importance, but one ought to get a little short of breath every day and get the feeling that the muscles have been used ... Workouts should be regular, preferably done every day, but at least three times a week. As a rule of thumb, no less than half an hour's exercise a day ... and we have come far in the prevention of osteoporosis and its consequences. (Health journal, special issue on menopause, article written by a physician employed by the National Health Agency, Bendix, 1994: 18)

The last decades have seen a growing focus on lifestyle and the individual's ability and responsibility to keep healthy. Good health and physical fitness are increasingly valued and promoted, and menopausal symptoms and osteoporosis risk are seen to be modifiable by lifestyle changes. This discourse has many similarities with those above, in particular its goal of avoiding diseases and loss of youthfulness. But decay and ill-health are seen both as caused by hormone deficiency and as the result of unhealthy lifestyle. The health-promoting discourse thus focuses on changes in lifestyles where menopausal women are obliged to be fit, to stop smoking and follow dietary recommendations. This gives them a much more active role, but medical experts remain the owners of the 'right' answers and they set the agenda, as seen in the example: a woman can choose whatever form of sport, as long as she gets half an hour of exercise every day. The illustrations often show sporty, fit and happy women in jogging outfits and sweatbands. The health-promoting discourse appears in most materials, particularly health 
newspapers, magazines and booklets. This health-promoting discourse has gained recent ground as a 'first line' strategy, among others because medical experts no longer consider hormone therapy an appropriate preventive strategy for healthy women (European Agency for the Evaluation of Medicinal Products (EMEA), 2003).

\section{Consumer discourse}

I consider myself completely neutral with regard to whether women should choose hormonal treatment, herbal medicine or something else. The woman should consult her doctor who will explain to her the advantages and disadvantages of different treatments. With that knowledge the woman can talk to her doctor to have her treatment tailored according to personal situation such as genetics, the family and work situation, lifestyle, symptoms, etc. But she alone can make the choice! (Olesen, H., Interview with Dr. Annette Tonnes Pedersen, 'Hormone therapy or not' (in Danish), Femina 27, 77-79)

Consumerism is gaining ground also in health services, where treatment and disease prevention become consumer goods. In this discourse, patients are consumers and doctors service providers or health advisers. This raises a demand for consumer rights, information, quality control, options for complaints and preferably a free and autonomous choice between all services.

Menopausal women are seen as active, informed and educated, and as having consumer rights. This discourse challenges the biomedical discourse by putting the consumer first. The importance of getting better information about menopause and available options is often stressed as crucial to women's control over their own health. Women are, however, encouraged to consult a doctor and are supposed to choose among treatments considered relevant by the GP and the public health authorities. The doctor's agenda therefore still dominates.

The illustrations in printed material often show resourceful women, for example having a conversation in a cafe, or they show a woman and a doctor talking, with the prescription form in the centre of the image.

\section{The alternative discourse}

Women of today have become heavy users of artificial hormones and other chemical medicine from adolescence to menopause ... In reality, most of the problems can be prevented or cured through changes in diet and lifestyle. In addition, there are many medicinal herbs, which are a fantastic gift to the woman's hormone system. Well-being is fundamentally about harmony. (Excerpt from a book on herbal medicines and hormonal imbalances, Lund, 2001: 7)

This discourse offers an alternative to the biomedical discourse, particularly by offering a non-medical treatment of symptoms, and by considering menopause a natural phase, even if the woman's body is off balance for a period. Transition and ageing are not viewed as a disease or a risk factor, but as an opportunity for development or as the start of a new phase in life. 
It is connected to the feminist and the existential discourses (see below). Treatment of bodily imbalances centre on the use of phytoestrogens, for example tofu and other herbal products with similar effects, but other methods like acupuncture are not uncommon. Medical drugs are considered toxins which burden the body and they are therefore to be avoided. There is also much critique of doctors who uncritically recommend medical treatment. Doctors are set aside and women are suggested to buy herbal medicine for themselves without consulting a doctor first. Alternative therapists are awarded higher status.

The alternative discourse is represented in booklets and material aiming at selling herbal medicine, but also in books and pamphlets written by alternative therapists. The illustrations often use motifs from nature, like flowers or landscapes and, if women are depicted, they look happy.

\section{The feminist/critical discourse}

About 30 per cent of all Danish women above 50 use oestrogen for shorter or longer periods. This treatment has been emotionally charged by both doctors and patients from the very beginning. Should menopausal problems be treated at all? Indeed, all women reach menopause. Doesn't it represent a medicalization of women's natural course through life? And even if some have a genuine need of treatment for some of the symptoms such as hot flushes, is it reasonable to use hormones also for prevention as proposed by certain doctors, particularly gynaecologists, and not surprisingly by the pharmaceutical industry, which would gain a secure source of income? Through the years there has been a tremendous amount of pressure from these two groups to ensure that all women from 40 and up should receive preventive treatment with oestrogen. (Newspaper chronicle, by feminist researcher, Petersson, 20 August 2002)

While the eternal youth, the health-promoting and the consumer discourses on the whole are compatible with the biomedical discourse, the feminist/ critical discourse stands in direct opposition to it. Its starting point is the existing inequality of power between women and men in society. Its aim is to expose and oppose any oppression found, and the prevailing strong focus on menopausal hormone deficiency and the medicalization of menopause is heavily criticized.

The critique and the arguments are central in this discourse and no fixed image of menopausal women is created. It is stressed that menopause is a natural process and that women's experience may vary. Women are often described as being oppressed by men, doctors or pharmaceutical interests, and symptoms and ill-health are often seen as a result of other events in women's lives, such as bad working conditions, long working hours and being worn out. Women are fundamentally seen as strong and capable; a viewpoint that is closely related to the existential discourse (see below).

Referring to menopausal women as oppressed and medicalized may create an image of women as passive victims. On the other hand, the image of women as active is supported by recommendation that women should 
seek more knowledge about their bodies and possible ways of handling menopause, also without medicine. The doctors' expert role in relation to women is actively downplayed, partly by opposing the medicalization of a natural period in women's life, partly by giving women a more active role by being better informed and therefore capable of making their own choices, independently of the doctors' recommendations.

The feminist discourse is most frequent in books written by feminist authors with the explicit goal of contributing to increase women's knowledge. It is also seen in newspaper chronicles, columns and letters to the editor as commentaries to and critiques of medicalization. The feminist viewpoint is almost wholly absent in the many booklets and health-promotion articles written by medical experts and the pharmaceutical industry.

The illustrations often show healthy women whose strength is intrinsic to them, or they depict oppression or medicalization.

\section{The existential discourse}

It is not the end of the world to be climacteric - quite the contrary!

... In reality menopause is a transition to a phase in life where you will have other options and enjoy more freedom. More maturity, life experience and selfconfidence. No menstruation and no risk of pregnancy. Menopause can easily be a flowering period filled with quality of life. (From a commercial for a herbal medicine, Maxmedica Bodycare, 2000)

The existential discourse offers the greatest potential for changing the negative images of deficiency syndrome, ageing decay and the hunchbacked crones. In this material, menopause, hormonal changes and symptoms are sometimes not even mentioned, and the subject is merely mid-life changes as part of ageing. The primary concern is the ability to 'take on life' for better or worse in loss as well as joy. Symptoms and diseases exist, but are not necessarily seen as something negative, but as inevitable parts of life itself, carrying possibilities for personal development. Menopause is seen as one of many transitions in life, with many positive options both in relation to menopause itself and as a means of starting a new phase in life. It offers the opportunity of getting more experienced and achieving greater levels of competence, as well as getting better at prioritizing and voicing one's opinion. At the same time, changes in the family situation give more time to pursue one's own interests and for many the new joy of becoming a grandmother.

The doctors play no noticeable role in this discourse which is exclusively concerned with the women and commonly represented in psychological literature, in 'new age' literature on personal development and in newspaper articles on existential issues. Besides, poetry and drama, as well as fairy tales and myths, deal with personal development and existential questions and problems. 
Illustrations show images of strong, well-functioning women who dare be themselves.

\section{The Danish setting in a global context}

The results obtained in the Danish setting show strong similarities with the results of studies from the USA, Australia and Great Britain (Gannon and Stevens, 1998; Lyons and Griffin, 2003; Shoebridge and Steed, 1999; Stephens et al., 2004). The biomedical discourse dominates our material as well as materials from the other countries, and it illustrates that menopause is articulated in much the same manner all over the western world and that discoursive struggles exist everywhere. This similarity is rooted in the strong American cultural influence in this field and in the transnational nature of medical knowledge communication where English is the international lingua franca and multinational pharmaceutical companies market their products across borders.

Differences do exist and can be ascribed partly to changes over time, partly to cultural differences.

The biomedical discourse has changed. When Bell described the medicalization of menopause in 1987, there was almost total agreement between the biomedical and what we call the 'eternal youth discourse'. Dr Robert Wilson published the book Feminine forever in 1966, which caused hormone sales in the USA to boom and to spread to the rest of the world. The argument was basically that the use of hormones after menopause could prevent an inevitable loss of femininity; an argument also backed by other medical experts. But after publication of studies falsifying myths associated with the uncountable symptoms of menopause (Avis and McKinlay, 1995; Dennerstein, 1996), a gradual separation of the two discourses occurred. Medical expertise no longer accepts the idea that hormones can secure 'eternal youth'.

The biomedical discourse has also been shaped by the data from the WHI (Writing Group for the Women's Health Initiative Investigators, 2002): almost no booklets or informational material praising hormones have been published since the publishing of these data. It seems as the biomedical discourse becomes dominant when a medical treatment becomes feasible, and that it loses terrain when the medical treatment can no longer be recommended for healthy women.

A New Zealand study (Stephens et al., 2004) identified a discourse dubbed 'marriage discourse' that stresses the need for a woman to use hormones in order to uphold her status as a housewife and the centre of the family. This discourse was not found in our material. Danish women are part of the work-force to a far greater extent than in many other countries and therefore are not as threatened by changes in the role of mother and spouse induced by menopause. It may also be that it is not a discourse Danish women wish to give voice to. 
An important part of the biomedical discourse is the focus of risk of oncoming diseases, such as osteoporosis.

Earlier findings from this and other studies have demonstrated how perception of risk of osteoporosis in relation to menopause may differ across cultural settings. In the Danish setting, it seemed to be part of a culturally embedded knowledge (Hvas et al., 2005) that surfaced during the interviews with women as a sign of the 'risk society' (Beck, 1994). However, in a British study, Backett-Milburn et al. (2000) reported that osteoporosis was only found to be a particularly salient issue among women who had personal experience with the condition. In this and in another British study by Ballard (2002), menopausal women only rarely mentioned the risk of osteoporosis spontaneously. The prominent role of images of old hunchbacked women in Denmark may result from the strong effect of pictures of the late Danish Queen mother, who was severely affected by osteoporosis before her death in November 2000. This has demonstrated to Danish women how serious a disease osteoporosis must be, since nothing could be done, not even for the Queen mother.

\section{Expanding or challenging the biomedical discourse?}

Even though as many as seven different discourses could be identified, they often worked together in certain combinations. Roughly there were two main groups: the biomedical, the eternal youth and the health-promotion discourse on one side and the alternative, feministic and existential discourse on the other. The consumer discourse occupies the middle ground.

Like other researchers, we found the biomedical discourse on menopause to be dominant (Bell, 1987; Lock, 1993), but we found the other discourses to either expand or challenge it. The eternal youth and healthpromotion discourses have much in common with the biomedical one, seeing menopause and ageing as a threat, but they also expand it, for example by offering other scopes of action like cosmetics, sports or healthy food to avoid symptoms and diseases later in life. On the other side, the feministic discourse challenges the biomedical one by directly opposing the concept of 'deficiency syndrome', and the image of the menopausal women thus constructed becomes identical to empowered women in the existential discourse, where menopause is seen as a natural part of life. Herbal medicine fits well into this picture, when it is taken in order to avoid dependence on medicine.

\section{Different discourses - different values and goals}

We have tried to elicit the kinds of values inherent within each discourse. In the biomedical discourse, the more or less implicit goal of avoiding diseases, decay and untimely death is seen as self-evident. If the focus is instead on 
how to attain or retain control over one's own life and health, or if there is acceptance of living a life of 'good and evil', then the biomedical discourse is challenged. The alternative, the feminist and the existential discourses all challenge the biomedical discourse by offering alternative values and more positive images of middle-aged and older women.

However, according to the discourse analytic approach - no discourse could be said to be 'better' or more 'true' than the other. The discourse analytic approach reveals how 'truth' and goals are constructed differently, but it gives no clue as to whether one or the other is better. As Foucault (1972) said, power becomes productive when, through attained positions of power, something is achieved. In the context of the present study, if the goal is to avoid disease, the biomedical discourse together with the healthpromotion discourse are likely to be the best way of achieving this goal. But if the goal is to maintain or develop positive images of the female ageing process, the existential, feministic and alternative discourses seem to offer better options. In this way, discourse analysis can be a means to highlight historical shifts in values and perspectives and to capture what the general society considers to be true or false.

Everything is a discursive construction, including the present article, because all knowledge is created contextually. Because a neutral, objective, 'true' or in Haraway's (1991) terminology a 'divine' perspective does not exist, our presentation will also have been shaped by its context; that is, both the feministic and sociological literature (Bell, 1987; Greer, 1991; Kaufert and Lock, 1997), which describes the biomedical discourse and its consequences for women in negative terms, and our own (Hvas, 2006), which captures and maintains positive images of menopausal women.

\section{How do the different discourses relate to women's identity?}

We have investigated how discourses construct and position women. Women's position varies noticeably from one discourse to another, which also has been described under each discourse above. For instance, being positioned as 'the patient' within the biomedical discourse means that the woman's body becomes an object of legitimate interest to doctors, that it may be exposed, touched and invaded in the process of treatment and examinations (Willig, 2003). The image of an autonomous and healthy woman, which is offered by other discourses, results in quite another powerful position.

Speaking of menopause, it therefore makes a difference whether we use words like 'deficiency syndrome' or 'a period with possibilities for personal development'. The choice shapes the image of menopausal women. 'Deficiency syndrome' indicates that women are in a state of loss, passively subjected to their biology and in need of hormone 'replacement' therapy. By contrast, stressing the developmental aspect gives women a more positive and active role where the woman is 'in charge'. 


\section{Is there a free choice, when the options are given beforehand?}

Every discourse offers different options and scopes of action. Values and positions are constructed within each discourse, which means that the solutions belonging to or inherent in a particular discourse are almost given beforehand. Thus, the biomedical discourse claims that menopause should be discussed with a doctor, and that hormone therapy is the best solution when symptoms occur; in contrast, the alternative discourse claims that herbal medicine is the solution. According to the existential discourse where menopause is seen as a period of life just like other developmental periods, menopause is more about taking 'life as it comes' and often medical solutions are avoided. The health-promotion discourse advocates healthy lifestyle as the solution, while spokesmen of the 'eternal youth discourse' offer several solutions: Botox, hormones, cosmetic surgery and hair colouring remedies, just to mention some.

But where Foucault himself tended towards describing one, and only one, knowledge regime, this understanding is now by most discourse analysts replaced by a more conflicting picture of different discourses existing in parallel, struggling to represent the truth (Phillips and Jorgensen, 2002).

Discourse analysis helps us to understand how different truths can exist simultaneously by constructing the 'truth' within each separate discourse, and by defining the boundaries within which each discourse defines what can be said at all and what is unthinkable.

This fact calls the 'informed choice' into question, since the number and nature of options open for choice depend on the discourse. For example, Murtagh and Hepworth (2003) question if women really have a free choice when they see their general practitioner (GP) in relation to menopause. They stress that the way 'the informed choice' works at present is an illusion, because choices are made on the doctors' premises. This study and the studies mentioned earlier find that within the context of menopause, the biomedical discourse prevails in western countries. But other, parallel discourses also exist, and when two discourses are in conflict with each other, a 'discoursive struggle' evolves (Phillips and Jorgensen, 2002). According to critical discourse analysis, this struggle is decisive for social change (Fairclough, 1992), because it offers subjects different positions and thereby allows a change in power relations.

Murtagh and Hepworth (2003) demonstrate that the use of concepts from the women's health movement and health promotion has triggered a change in both women's position as having 'choices' and the GPs' behaviour, which has shifted towards greater information provision to women and growing attention to the woman's autonomy. They propose that a new menopause has evolved from a discursive shift in medicine and that, within this new configuration, women's empowerment is enhanced as an integral part of health care for menopause. They also suggest the possibility of a change in medical practice that will broaden, strengthen and maintain this new position. 


\section{Conclusion}

The biomedical discourse prevails in printed texts about menopause, but several other discourses can be distinguished that offer other positions and ways to act. Doctors involved in the counselling of menopausal women should be aware that the medical way of constructing menopause is just one of many, and that the medical goal of avoiding disease or death sometimes competes with other values in people's lives. Depending on the discourse drawn upon, the woman's position can be that of a passive patient or that of an empowered woman, capable of making her own choices in relation to her health.

\section{References}

Avis, N.E. and McKinlay, S. (1995). The Massachusetts Women's Health Study: An epidemiologic investigation of the menopause. Journal of the American Medical Women's Association, 50(2), 45-9.

Backett-Milburn, K., Parry, O. and Mauthner, N. (2000). 'I'll worry about that when it comes along': Osteoporosis, a meaningful issue for women at mid-life? Health Education Research, 15(2), 153-62.

Ballard, K. (2002). Understanding risk: Women's perceived risk of menopauserelated disease and the value they place on preventive hormone replacement therapy. Family Practice, 19(6), 591-5.

Beck, U. (1994). The reinvention of politics, towards a theory of reflective modernization. In U. Beck, A. Giddens and S. Lash (Eds.), Politics, tradition and aesthetics in the modern social order, pp. 1-55. Cambridge: Polity Press.

Bell, S.E. (1987). Changing ideas: The medicalization of menopause. Social Science and Medicine, 24(6), 535-42.

Bendix, A.F. (1994). Motion Styrker [Health strengthens]. Helse, 10, 18.

Bertero, C. (2003). What do women think about menopause? A qualitative study of women's expectations, apprehensions and knowledge about the climacteric period. International Nursing Review, 50(2), 109-18.

Blaakilde, A.L. (2001). Old age, cultural complexity, and narrative interpretation. In D.N. Weisstub, D.C. Thomasma, S. Gauthier and G.F. Tomossy (Eds.), Ageing: Culture, Health, and Social Change, pp. 175-89. Netherlands: Kluwer Academic Publishers.

Daly, J. (2001). Facing change, women speaking about midlife. In P. Komesaroff, P. Rothfield and J. Daly (Eds.), Reinterpreting menopause, pp. 159-75. London \& New York: Routledge.

Dennerstein, L. (1996). Well-being, symptoms and the menopausal transition. Maturitas, 23(2), 147-57.

Dennerstein, L., Smith, A.M. and Morse, C. (1994). Psychological well-being, midlife and the menopause. Maturitas, 20(1), 1-11.

European Agency for the Evaluation of Medicinal Products (EMEA). (2003). EMEA public statement on recent publications regarding hormone replacement therapy, 3 December. http://www.emea.eu.int/pdfs/human/press/ pus/3306503en.pdf

Fairclough, N. (1992). Discourse and social change. Cambridge: Polity Press.

Felding, C. and Christoffersen, C. (2004). Overgangsalderen [Menopause]. Dit lagemagasin [Your Health magazine], 6, 18-21. 
Ferguson, S.J. and Parry, C. (1998). Rewriting menopause: Challenging the medical paradigm to reflect menopausal women's experiences. Frontiers, 19(1), 20-41.

Foucault, M. (1972). Truth and power. In C. Gordon (Ed.), Power and knowledge, pp. 109-33. New York: Pantheon Books.

Gannon, L. and Stevens, J. (1998). Portraits of menopause in the mass media. Women-Health, 27(3), 1-15.

Greer, G. (1991). The change. London: Hamish Hamilton.

Haraway, D.J. (1991). Simians, cyborgs, and women. London: Routledge.

Hvas, L. (2001). Positive aspects of menopause: A qualitative study. Maturitas, $39(1), 11-17$.

Hvas, L. (2006). Menopausal women's positive experience of growing older. Maturitas, 54(3), 245-51.

Hvas, L., Søndergaard, K. and Thorsen, H. (2003). Discussing menopause in general practice. Maturitas, 46(2), 139-46.

Hvas, L., Reventlow, S., Jensen, H.L. and Malterud, K. (2005). Awareness of risk of osteoporosis may cause uncertainty and worry in menopausal women. Scandinavian Journal of Public Health, 33(3), 203-7.

Hvas, L. and Gannik D.E. (2008). Discourses on menopause - Part II: How do women talk about menopause? Health: An Interdisciplinary Journal for the Social Study of Health, Illness and Medicine 12(2), 177-192. London: SAGE.

Kaufert, P.A. and Lock, M. (1997). Medicalization of women's third age. Journal of Psychosomatic Obstetrics \& Gynaecology, 18(2), 81-6.

Laclau, E. and Mouffe, C. (1985). Hegemony and socialist strategy. London: Verso.

Lock, M. (1993). The politics of mid-life and menopause: Ideologies for the second sex in North America and Japan. In S. Lindenbaum and M. Lock (Eds.), Knowledge, power and practice, pp. 330-63. Los Angeles, CA: University of California Press.

Lund, P. (2001). Det er hormonerne [It is the hormones]. Copenhagen: Klitrose.

Lupton, D. (1996). Constructing the menopausal body: The discourses on hormone replacement therapy. Body and Society, 2(1), 91-7.

Lyons, A.C. and Griffin, C. (2003). Managing menopause: A qualitative analysis of self-help literature for women at midlife. Social Science and Medicine, 56(8), $1629-42$.

Maxmedica Bodycare. (2000). Remifemin [pamphlet].

Murtagh, M.J. and Hepworth, J. (2003). Menopause as a long-term risk to health: Implications of general practitioner accounts of prevention for women's choice and decision-making. Sociology of Health and Illness, 25(2), 185-207.

Nexø, S.A. and Koch, L. (2003). Diskursanalyse - et særligt blik på verden [Discourse analysis - a special look at the world]. In L. Koch and S. Vallgårda (Eds.), Forskningsmetoder i folkesundhedsvidenskab [Research methods in public health], pp. 69-90. Copenhagen: Munksgaard Danmark.

Petersson, B. (2002). Hormoner en masse [Hormones en masse]. Politiken, 20 August.

Phillips, L. and Jorgensen, M.W. (2002). Discourse analysis as theory and method. London: Sage Publications.

Potter, J. and Wetherell, M. (1987). Discourse and social psychology. London: Sage Publications. 
Shoebridge, A. and Steed, L. (1999). Discourse about menopause in selected print media. Australian and New Zealand Journal of Public Health, 23(5), 475-81.

Skodsborg, P. (2001). Kvinder i overgang [Menopausal women]. Interview with executive in Organon, Lene Juncker-Jensen. Tidens voksne, 1, 13.

Stephens, C., Carryer, J. and Budge, C. (2004). To have or to take: Discourse, positioning, and narrative identity in women's accounts of HRT. health: An Interdisciplinary Journal for the Social Study of Health, Illness and Medicine, $8(3), 329-50$.

Tsao, A. (2003). Cosmetic-services stocks pretty up. Business Week Online, 16 December.

Utian, W.H. and Boggs, P.P. (1999). The North American Menopause Society 1998 menopause survey. Part I: Postmenopausal women's perceptions about menopause and midlife. Menopause, 6(2), 122-8.

Willig, C. (2003). Discourse analysis. In J. Smith (Ed.), Qualitative psychology: A practical guide to research methods, pp. 159-83. London: Sage Publications.

Wilson, R.A. (1966). Feminine forever. Philadelphia, PA: Lippincott Co.

Writing Group for the Women's Health Initiative Investigators (WHI). (2002).

Risks and benefits of estrogen plus progestin in healthy postmenopausal women: Principal results from the Women's Health Initiative randomized controlled trial. Journal of the American Medical Association, 288(3), 321-33.

\section{Author biographies}

LOTTE HVAS is an MD and Specialist in Family Medicine. She is affiliated to the Department of General Practice and Research Unit for General Practice, University of Copenhagen, Denmark. She has conducted a research project on 'Menopause seen from the women's perspective', a project combining qualitative and quantitative data. She has published several articles on women's experiences on menopause and on women's experiences on risk of osteoporosis. Besides her research she works as a general practitioner.

DORTE EFFERS $\emptyset$ E GANNIK was trained in sociology and is a doctor of social science and an associate professor in the Research Unit for General Practice, Copenhagen, Denmark. Her research deals mainly with the everyday life context of disease and illness, but she has published also on the structural problems of primary health care. Currently, she is investigating the significance and interpretation of symptoms associated with cardiovascular disease. 